\title{
Efectos de la Aplicación de un Sistema de Evaluación Formativa en la Autopercepción de Competencias Adquiridas en Formación Inicial del Profesorado*
}

\author{
Effects of the Application of a Formative and Shared Assessment System on the \\ Self-perception of Competences Acquired in Pre-service Teacher Education
}

\author{
Francisco Gallardo-Fuentes ${ }^{a}$, Víctor M. López-Pastor ${ }^{b}$, Bastian Carter-Tuhillier ${ }^{c}$ \\ a Departamento Ciencias de la Actividad Física, Universidad de Los Lagos, \\ Telf.: (56) 642333132, Correo electrónico: fgallardo@ulagos.cl \\ ${ }^{\mathrm{b}}$ Facultad de Educación de Segovia, Universidad de Valladolid \\ ${ }^{\mathrm{c}}$ Facultad de Educación, Universidad Católica de Temuco
}

\section{RESUMEN}

El objeto de estudio es analizar la valoración del alumnado sobre el sistema de evaluación formativa y compartida (EFyC) utilizado en la asignatura "Fundamentos y didáctica de la Educación corporal en Educación Infantil", así como la autopercepción de competencias profesionales adquiridas durante la misma. Se ha llevado a cabo en una Facultad de Educación española bajo diseño de pre y pos-test en una muestra de 93 alumnos, de dos grupos y cursos: (a) Titulación Maestro, Grado en Educación Infantil (MGEI); y, (b) Plan de Estudios Conjunto de Educación Primaria y Educación Infantil (PECEPI). Para la recogida de datos se aplican dos escalas previamente validadas: el "Cuestionario de evaluación sobre la asignatura" y una "Escala para la autopercepción de competencia de los estudiantes". Los resultados muestran una alta valoración de las "ventajas" del sistema de EFyC utilizado, mientras que la mayoría de los "inconvenientes" recibieron bajas valoraciones. Respecto a la autopercepción de adquisición de competencias, la mayoría de las valoraciones del alumnado son más elevadas en el pos-test. Los datos recogidos confirman las ventajas que tiene la utilización de sistemas de EFyC en la formación inicial del profesorado y su posible aportación en el desarrollo de competencias profesionales. Es necesario realizar más investigación sobre este último aspecto.

Palabras claves: evaluación compartida, educación superior, educación infantil, educación primaria, educación física.

\begin{abstract}
The objective of this study was to analyze students' valuation of the system of formative and shared assessment (F\&SA) utilized in the course "Fundamentals and didactics of body education in childhood education," as well as their self-perception of the professional skills acquired during the course. It was carried out in a Faculty of Teacher Education at a Spanish university using a pre- and post-test design with a sample of 93 students, which was composed of two groups and courses: (a) Teaching Degree in Childhood Education (TCHE) and (b) Joint Curriculum for Childhood Education and Primary Education (JCCH\&PE). The results show a high appraisal of the "advantages" of the F\&SA system, while the majority of the "disadvantages" received lower
\end{abstract}

Este estudio se ha llevado a cabo dentro del proyecto de I+D+i: "Las competencias docentes en la formación inicial del profesorado de Educación Física". Convocatoria de noviembre de 2013 del Programa Estatal de Investigación, Desarrollo e Innovación Orientada a los Retos de la Sociedad, en el marco del Plan Estatal de Investigación Científica y Técnica y de Innovación 2013-2016. Referencia: EDU 2013-42024-R. Duración: 3 años (2014-2017) 
results. Regarding self-perception of the acquisition of competences, most students indicated higher scores on the post-test, so we conclude that the F\&SA system helped improve their competences. The data collected confirm the advantages of using F\&SA systems in pre-service teacher education and their possible contribution to the development of professional skills. It is necessary to carry out more research on the latter.

Keywords: co-assessment, higher education, childhood education, primary education, physical education.

\section{INTRODUCCIÓN}

\subsection{LA EVALUACIÓN FORMATIVA Y COMPARTIDA EN LA FORMACIÓN INICIAL DEL PROFESORADO}

Según Ibarra, Rodríguez y Gómez (2012), durante muchos años se ha entendido que los procesos de enseñanza-aprendizaje (E-A) están inmersos en un ciclo de entrega de conocimiento y constatación de logro de estos mismos; pero que dicha constatación estaba centrada en la cultura de la calificación, que ha demostrado ser poco o nada útil en el proceso E-A. Se trata de una tradición que parece estar cambiando, en la que el papel del alumnado ha cobrado mayor importancia, situándose en el centro del proceso E-A (Biggs, 2005). En este sentido, Bozu y Canto (2009) afirman que la enseñanza universitaria debería preocuparse de desarrollar las capacidades del alumnado; mientras que Dochy, Segers y Dierick (2002) defienden que la universidad europea tiene que comenzar a superar la "cultura del examen" y avanzar más en la "cultura de la evaluación".

La literatura especializada sobre esta idea de avanzar en la "cultura de la evaluación" muestra numerosas experiencias de éxito de evaluación formativa y compartida (EFyC) desarrolladas y evaluadas en los últimos 20 años (Biggs 2005; Gallardo \& Carter, 2016; Hamodi, López \& López-Pastor, 2014; Knight 2005; López-Pastor, 2009; López-Pastor \& Pérez-Pueyo, 2017; López-Pastor et al., 2016). Se entiende por "evaluación formativa" (EF) aquella que mejora los procesos de E-A, o como la define López-Pastor (2012) "es todo proceso de evaluación cuya finalidad principal es mejorar los procesos de E-A que tienen lugar; está orientada a que el alumnado aprenda más y a que el profesorado aprenda a mejorar su práctica docente" (p. 120). Por otro lado, la "Evaluación Compartida" es aquella en la que se implica al alumnado en los procesos de evaluación, siendo fundamental el diálogo y la toma de decisiones conjunta entre el docente y discente" (López-Pastor, 2009, p. 37).

La literatura especializada también muestra una estrecha relación entre la Formación Inicial del Profesorado (FIP) y la EFyC, dado el gran número de estudios con experiencias de éxito documentadas que demuestran la eficacia de los sistemas de EFyC en FIP (BarbaMartín \& López-Pastor, 2017; Biggs 2005; Castejón et al., 2011; Gallardo \& Carter, 2016; Hamodi et al., 2014; Knight, 2005; López-Pastor, 2008, 2009, 2012; López-Pastor et al., 2016; Martín, 2007; Romero-Martín et al., 2017). Por otra parte, muchos de estos estudios muestran que tanto el alumnado como el profesorado valoran positivamente su uso en los procesos de E-A en FIP. Recientes estudios hacen referencia a la transferencia que existe entre la utilización de sistemas de EFyC durante la FIP y el desarrollo y aplicación de este tipo de sistemas en su vida profesional cuando los estudiantes acceden posteriormente a puestos de trabajo como maestros (Hamodí et al., 2017; Molina \& López-Pastor, 2017). Se trata de un proceso lógico, dado que diferentes investigaciones hacen recordar que el 
profesorado tiende a utilizar como métodos evaluativos los que fueron utilizados con ellos cuando eran alumnos (Palacios \& López-Pastor, 2013).

En muchos de los estudios sobre experiencias de EFyC señalados, una actividad de aprendizaje muy coherente es la denominada: "Proyectos de Aprendizaje Tutorados" (PAT). Los PAT consisten en una actividad de aprendizaje grupal que, normalmente, implica la realidad de una práctica (real o simulada), donde se ponen en juego diferentes competencias profesionales. La elaboración del proyecto implica la realización de una serie de borradores que se revisan con el tutor, recibiendo feedback y mejorándolos, hasta que tienen la calidad suficiente para ponerlos en práctica con el resto de sus compañeros. De esta forma se asegura una calidad mínimamente aceptable en la puesta en práctica y en la documentación a entregar a sus compañeros. Se trata de una metodología didáctica muy potente en FIP, que en los últimos 15 años ha demostrado ser una forma muy eficaz de trabajo teóricopráctico y de desarrollo de competencias profesionales. Pueden encontrarse trabajos en que se explica a fondo estas experiencias y su organización en Manrique-Arribas, LópezPastor, Monjas y Real-Rubio (2010), Barba-Martin, López-Pastor, Manrique-Arribas, Gea y Monjas (2010), y López-Pastor, Manrique-Arribas, Monjas y Gea (2010).

\subsection{LA EVALUACIÓN FORMATIVA Y COMPARTIDA EN LA FIP DE EDUCACIÓN INFANTIL}

En el apartado anterior se ha hecho referencia a las ventajas que la EFyC tiene en el proceso de E-A en educación superior, especialmente relevante en FIP. Por ejemplo, en el grado de Maestro en Educación Infantil (MGEI) pueden encontrarse experiencias documentadas de la efectividad de los sistemas de EFyC (Barba-Martín \& López-Pastor, 2017; González \& Wagenaar, 2003; Gutiérrez, 2017; Martínez-Mínguez, 2016). Otros trabajos ponen el foco de atención en que los sistemas de EFyC permiten que el alumno tome conocimiento de su nivel competencial y que el profesorado pueda mejorar su labor docente y sus asignaturas año a año (Manrique-Arribas, Vallés \& Gea, 2012), así como que facilita que el alumnado de FIP pueda posteriormente transferirlo en su práctica profesional futura (Hamodí et al., 2017). Por todo ello, parece importante que el profesorado de FIP en MGEI incorporé sistemas de EFyC en sus asignaturas sí pretendemos que luego el alumnado en formación los aplique y trasfiera en su futuro trabajo docente en el aula de educación infantil.

\subsection{LA AUTOPERCEPCIÓN DE COMPETENCIAS EN FORMACIÓN DEL PROFESORADO}

Durante muchos años ha primado como eje de la enseñanza la figura del profesor y su docencia, normalmente en base a la metodología didáctica de "lección magistral". Este paradigma formativo "Centrado en el profesor" se ha reproducido durante tantos años que ha llegado a convertirse en el paradigma tradicional utilizado en el proceso de E-A universitario (De Miguel, 2005). El cambio hacia un paradigma educativo centrado en el estudiante parece estar muy relacionado con la introducción y generalización del paradigma centrado en el "desarrollo de competencias" (Benito \& Cruz, 2003; Biggs, 2005; Knight, 2005; Zabalza, 2001, 2003). Sobre este aspecto, Bozu y Canto (2009, p. 91) afirman: "un perfil basado en competencias se centra en el desarrollo de capacidades en los sujetos, favoreciendo la formación de profesionales críticos y reflexivos, autónomos y responsables en su desempeño profesional”. En los últimos años se pueden encontrar diferentes investigaciones que abordan la percepción del alumnado sobre la adquisición 
de competencias (Gutiérrez-Castillo \& Cabero-Almenara, 2016; Villamizar, Becerra \& Delgado, 2016). En estas investigaciones podemos encontrar casos en los que el alumnado se percibe como medianamente competente y esta percepción decrece aún más cuando avanzan en su proceso formativo. Puede estar influenciado porque las prácticas al final de su FIP les permiten confrontar con la realidad y ser más conscientes de los desafíos que la profesión supone. También hay quienes sitúan los estudios de percepción de competencias como una herramienta valiosa (Mas-Torelló \& Olmos-Rueda, 2016; Rodrigo-Alsina \& Almiron, 2013), porque puede ayudar a identificar posibles problemas en la adquisición de alguna competencia específica en alguna disciplina.

Con respecto a la percepción de competencias de alumnado de FIP, se pueden encontrar investigaciones que revelan las ventajas de los sistemas de EFyC en la adquisición de competencias. Por ejemplo, el alumnado indica que estos sistemas de evaluación contribuyen a mejorar sus competencias éticas, de trabajo en equipo y sus habilidades interpersonales, así como sus competencias docentes, manifestando que esto se debe principalmente a la interacción profesor-estudiante. Aunque también se han encontrado resistencias de parte del alumnado, que manifiesta problemas de comprensión del sistema de EFyC, aunque valoran positivamente la retroalimentación que el docente entrega (Aparicio \& FraileAranda, 2015; Hortigüela-Alcalá, Pérez-Pueyo \& Abella-García, 2015; Hortigüela-Alcalá et al., 2016; Romero-Martín et al., 2017).

\subsection{LA INFLUENCIA DE LA EVALUACIÓN FORMATIVA Y COMPARTIDA EN LA AUTOPERCEPCIÓN DE COMPETENCIAS PROFESIONALES EN FORMACIÓN DEL PROFESORADO}

Hemos encontrado pocos estudios que vinculen la aplicación de procesos de EFyC con la autopercepción del alumnado sobre sus competencias profesionales, sin embargo, es relevante ahondar más en este tema, especialmente cuando el modelo de competencias se está instalando en las estructuras universitarias europeas desde hace algo más de una década (Espacio Europeo de Educación Superior [EEES]), a partir del modelo curricular de base utilizado en la reforma de las titulaciones: Proyecto "Tuning Educational Structures in Europe" (González \& Wagenaar, 2003). Además, este modelo ha sido adoptado desde hace varios años en Sudamérica. Concretamente, en Chile, la universidad estatal de Talca ha sido la pionera, al rediseñar su estructura curricular adoptando el modelo por competencias en el año 2006 (Hawes \& Corvalán, 2005; Quezada, 2014).

En todo caso, tal como explica Biggs (2005), la evaluación es la que condiciona qué y cómo se aprende, de manera que es una condicionante importante en el proceso de aprendizaje del alumnado. Por ello nos interesa explorar las relaciones que se establecen entre el sistema de evaluación utilizado $(\mathrm{EFyC})$ y la autopercepción de competencia del alumnado en FIP.

\section{OBJETIVO}

Por todo lo dicho anteriormente, los objetivos del estudio son los siguientes:

1. Analizar la valoración que el alumnado de dos titulaciones (MGEI y PECEPI) realiza sobre una asignatura que utiliza un sistema de EFyC en FIP. 
2. Analizar la autopercepción del alumnado de las dos titulaciones (MGEI y PECEPI) sobre las competencias profesionales adquiridas durante una asignatura que utiliza un sistema de EFyC en FIP.

\section{MÉTODO}

El diseño metodológico podría considerase "estudio de caso", dado que, al estudiar una realidad particular en su propia manifestación, ésta constituye un caso en sí misma (Stake, 2010). En primer lugar, se desarrolló todo el proceso de E-A de la asignatura, con un sistema de EFyC.

La asignatura se imparte a dos grupos de forma paralela, durante el segundo cuatrimestre del curso: (a) MGEI, de tercer curso de grado; (b) PECEPI, de primer curso del doble plan de estudios de grado. Los participantes formaron parte de la investigación de forma voluntaria y se respetaron en todo momento los estándares éticos contenidos en la Declaración de Helsinki 2013.

\subsection{MUESTRA}

El estudio se desarrolló con 93 alumnos y alumnas de la misma facultad de Educación de una universidad española: 52 del grado MGEI y 41 de PECEPI. La edad media del alumnado de MGEI es de 23,5 años, con una desviación típica $(d t$.) de 0.8; mientras que en el grupo de PECEPI la edad media es de 18,5 años, con una $d t$. de 0.3 .

\subsection{SISTEMA DE EVALUACIÓN UTILIZADO}

Se utilizó un sistema de EFyC que ofrece una triple vía de aprendizaje y evaluación al alumnado (continua, mixta y final), en función del grado de cumplimiento del alumnado de los requisitos establecidos. La evaluación "continua" implica asistir regularmente a clase, entregar todas las evidencias en la fecha y forma adecuada (normalmente una o dos por semana). El profesor devuelve todas las evidencias corregidas y con feedback en el plazo máximo de una semana (normalmente al día siguiente de su entrega). Si alguna evidencia no supera los niveles mínimos establecidos, el alumnado tiene la obligación de corregirla y entregarla en un plazo máximo de una semana. La actividad de aprendizaje más importante de la asignatura es el PAT, que consistía en la preparación de una sesión práctica y un marco teórico sobre uno de los temas de la asignatura. Al finalizar el proceso de E-A se lleva a cabo un proceso de autoevaluación y evaluación compartida. La Tabla 1 muestra un resumen de las actividades de aprendizaje básicas que se realizan regularmente, así como su relación con el instrumento de evaluación formativa utilizado para dar el feedback y el peso que tiene dicha actividad en la calificación final. Los estatutos de las universidades españolas establecen una clasificación numérica de 0 a 10, donde el suficiente se obtiene con un 5 . 
Estudios Pedagógicos XLIV, $\mathrm{N}^{\circ}$ 2: 55-77, 2018

EFECTOS DE LA APLICACIÓN DE UN SISTEMA DE EVALUACIÓN FORMATIVA EN LA AUTOPERCEPCIÓN DE COMPETENCIAS ADQUIRIDAS EN FORMACIÓN INICIAL DEL PROFESORADO

Tabla 1. Actividades de evaluación y calificación utilizadas en la experiencia de EFyC

\begin{tabular}{|l|l|c|}
\hline Actividades de aprendizaje & Instrumento de evaluación & Peso en calificación final \\
\hline Proyecto de Aprendizaje Tutorado (PAT) & Escala Descriptiva (rúbrica) & $30 \%$ \\
\hline Trabajo grupal sobre el currículum de EI & Escala Descriptiva (rúbrica) & $10 \%$ \\
\hline Fichas de sesiones prácticas & Escala Descriptiva (rúbrica) & $20 \%$ \\
\hline Examen parcial con co-Evaluación inmediata & Plantilla de Corrección “ad hoc" & $20 \%$ \\
\hline Mapas conceptuales & Escala descriptiva (rúbrica) & $10 \%$ \\
\hline Recensiones sobre lecturas & Escala descriptiva (rúbrica) & $10 \%$ \\
\hline
\end{tabular}

Nota: Ponderación de cada actividad de aprendizaje en la calificación final

La evaluación "mixta" implica asistir al menos al 50\% de las sesiones, realizar el PAT y aprobar el examen final. La evaluación "final" implica asistir a menos del 50\% de las sesiones. El alumnado que esté en esta situación tiene que realizar tres pruebas el día fijado oficialmente para la evaluación de la asignatura: un examen teórico, un examen práctico y la presentación y defensa de su PAT. Esta última opción existe porque así lo exige el reglamento de ordenación académica de la universidad.

Pueden encontrarse ejemplos y referencias de este tipo de sistemas de EFyC y sus resultados en Castejón-Oliva y otros (2011), Gallardo y Carter (2016) o López-Pastor (2008, 2009, 2012).

\subsection{INSTRUMENTOS DE OBTENCIÓN DE DATOS}

(1) "Cuestionario de evaluación sobre la asignatura". Recoge las valoraciones que el alumnado realiza sobre el sistema de EFyC empleado. Se trata de un cuestionario anónimo que consta de 30 ítems, con una escala tipo Likert de cinco grados, en donde $0=$ nada, $1=$ poco, $2=$ =algo, 3 =bastante, $4=$ mucho, en respuesta a las afirmaciones contenidas en una serie de ítems (ver tablas de resultados 2 y 3). Dicho cuestionario ha sido previamente validado (Castejón-Oliva, Santos-Pastor \& Palacios, 2015), presentando un coeficiente de .84 Alpha de Cronbach para toda la escala. En el presente estudio el análisis se centró en los ítems y variables que dan respuesta a los siguientes factores: (a) ventajas del sistema de Evaluación (16 ítems); (b) posibles desventajas del sistema de evaluación (14 ítems).

(2) "Escala para la autopercepción de competencia de los estudiantes". Mide la autopercepción de competencia del alumnado en tres tipos de competencias: "Transversales" (bloque I), "Docentes Generales" (bloque II) y "Docentes Específicas de Educación Física" (bloque III). La escala tiene 45 ítems agrupados en tres bloques: bloque I (14 ítems); bloque II (17 ítems); bloque III (14 ítems). Los ítems utilizan una escala tipo Likert de cuatro grados, en donde 1=nada; $2=$ poco; 3 =bastante y $4=$ mucho (ver tablas de resultados 4,5 y 6 ). La escala se aplica dos veces: (a) durante la primera semana del cuatrimestre (pre-test); y, (b) durante la última semana de clase (pos-test). La escala ha sido previamente validada por Salcines-Talledo y otros (2017), con un Alfa de Cronbach de .992 para el cuestionario global, y .962, .896 y .982 para cada una de los tres grandes bloques, respectivamente. 


\subsection{PROCEDIMIENTO}

La experiencia se desarrolló durante una asignatura de "Educación Física en Educación Infantil" en titulaciones propias de la FIP. En el grado MGEI, la asignatura se imparte en $6^{\circ}$ semestre de la carrera (tercer curso, segundo semestre), mientras que en PECEPI la asignatura se imparte en $2^{\circ}$ semestre (primer curso, segundo semestre). Por tanto, hay una diferencia importante en la formación previa y la edad media del alumnado de los dos grupos. Los análisis que se presentan corresponden al segundo semestre del curso académico 2016-2017.

Al principio de la asignatura se aplica la "Escala para la autopercepción de competencia de los estudiantes" (pre-test). Durante la asignatura se aplica el sistema de EFyC ya explicado. Al finalizar la asignatura se aplica el "Cuestionario de evaluación sobre la asignatura" y la "Escala para la autopercepción de competencia de los estudiantes" (postest).

\subsection{ANÁLISIS ESTADÍSTICOS Y DE DATOS}

Los datos recogidos con los dos instrumentos se analizaron de dos formas: (a) estadística descriptiva, con la obtención de la media aritmética $(M)$ y la desviación típica $(d t$.); (b) estadística inferencial, concretamente diferencia de medias (pre y pos-test), mediante la prueba de $U$ de Mann-Whitney $(U)$, tomando como valor de significancia $p \leq .05$.

\section{RESULTADOS}

\subsection{VALORACIÓN DE LAS VENTAJAS Y DESVENTAJAS DEL SISTEMA DE EFYC UTILIZADO}

Al analizar los datos del "Cuestionario de evaluación sobre la asignatura", con respecto a los ítems que hacen referencia a las ventajas del sistema de evaluación utilizado, podemos ver el grado de acuerdo del alumnado que participó de la experiencia en la Tabla 2.

Tabla 2. Medias y dt. en las titulaciones MGEI y PECEPI al factor "ventajas del sistema de evaluación" (valor medio, escala 0-4) (* indica diferencias significativas)

\begin{tabular}{|l|c|c|c|c|c|c|}
\hline Preguntas & \multicolumn{2}{|c|}{ MGEI } & \multicolumn{2}{c|}{ PECEPI } & \multicolumn{2}{c|}{ MGEI vs. PECEPI } \\
\hline & $\boldsymbol{M}$ & $\boldsymbol{d t}$. & $\boldsymbol{M}$ & $\boldsymbol{d t}$. & $\boldsymbol{U}$ & Sig. \\
\hline a) Ofrece alternativas a todos los estudiantes & 3.38 & .85 & 3.21 & .65 & 562.000 & .126 \\
\hline $\begin{array}{l}\text { b) Hay un contrato previo, negociado y } \\
\text { consensuado del sistema de evaluación }\end{array}$ & 3.33 & .94 & 3.00 & .90 & 537.000 & .051 \\
\hline $\begin{array}{l}\text { c) Está centrado en el proceso, importancia del } \\
\text { trabajo diario }\end{array}$ & 3.93 & .26 & 3.79 & .42 & 608.500 & .071 \\
\hline d) El estudiante realiza un aprendizaje activo & 3.84 & .37 & 3.79 & .42 & 674.500 & .585 \\
\hline
\end{tabular}


Estudios Pedagógicos XLIV, N $^{\circ}$ 2: 55-77, 2018

EFECTOS DE LA APLICACIÓN DE UN SISTEMA DE EVALUACIÓN FORMATIVA EN LA AUTOPERCEPCIÓN DE COMPETENCIAS ADQUIRIDAS EN FORMACIÓN INICIAL DEL PROFESORADO

\begin{tabular}{|c|c|c|c|c|c|c|}
\hline $\begin{array}{l}\text { e) Se plantea el trabajo en equipo de forma } \\
\text { colaborativa }\end{array}$ & 3.72 & .50 & 3.55 & .51 & 576.000 & .090 \\
\hline $\begin{array}{l}\text { f) El alumno está más motivado, el proceso de } \\
\text { aprendizaje es más motivador }\end{array}$ & 3.42 & .63 & 2.97 & .82 & 443.500 & $.003 *$ \\
\hline g) La calificación es más justa & 3.30 & .91 & 3.00 & .18 & 540.500 & .091 \\
\hline $\begin{array}{l}\text { h) Mejora la tutela académica (seguimiento y } \\
\text { ayuda al alumno) }\end{array}$ & 3.35 & .61 & 3.16 & .83 & 578.000 & .185 \\
\hline $\begin{array}{l}\text { i) Permite aprendizajes funcionales y } \\
\text { significativos }\end{array}$ & 3.63 & .49 & 3.22 & .70 & 406.500 & $.000 *$ \\
\hline j) Se aprende mucho más & 3.63 & .62 & 3.44 & .82 & 548.500 & .082 \\
\hline k) Mejora la calidad de los trabajos exigidos & 3.49 & .63 & 3.31 & .89 & 594.000 & .262 \\
\hline 1) Hay interrelación entre teoría y practica & 3.72 & .59 & 3.69 & .83 & 654.500 & .635 \\
\hline $\begin{array}{l}\text { m) Evalúa todos los aspectos posibles (saber, } \\
\text { saber hacer, saber estar o ser) }\end{array}$ & 3.64 & .93 & 3.31 & .89 & 539.000 & .104 \\
\hline $\begin{array}{l}\text { n) Hay retroalimentación y posibilidad de } \\
\text { corregir errores en documentos y actividades }\end{array}$ & 3.79 & .41 & 3.67 & .54 & 638.500 & .322 \\
\hline o) Se da un seguimiento más individualizado & 3.16 & .72 & 2.61 & .70 & 413.500 & $.001 *$ \\
\hline p) Requiere más responsabilidad & 3.74 & .44 & 3.76 & .61 & 692.000 & .816 \\
\hline
\end{tabular}

Nota: U=U de Mann-Whitney; M=Media; dt.= Desviación Típica; *=p $\leq .05$

En ambas titulaciones se observa una alta valoración en los ítems referentes a "ventajas del sistema de evaluación", destacando el ítem "Está centrado en el proceso, importancia del trabajo diario". En la mayoría de los ítems el grupo de MGEI realiza valoraciones más altas que los de PECEPI, pero solamente son significativas en tres ítems: "El alumno está más motivado, el proceso de aprendizaje es más motivador", "Permite aprendizajes funcionales y significativos", "Se da un seguimiento más individualizado".

En la Tabla 3 se presentan las valoraciones de los ítems que hacen referencia a las "posibles desventajas del sistema de evaluación".

Tabla 3. Medias y dt. en las titulaciones MGEI y PECEPI del factor "posibles desventajas del sistema de evaluación" (* indica diferencias significativas)

\begin{tabular}{|l|c|c|c|c|c|c|}
\hline Preguntas & \multicolumn{2}{|c|}{ MGEI } & \multicolumn{2}{c|}{ PECEPI } & MGEI vs. PECEPI \\
\hline & $\boldsymbol{M}$ & $\boldsymbol{d t}$. & $\boldsymbol{M}$ & $\boldsymbol{d} t$. & $\boldsymbol{U}$ & Sig. \\
\hline a) Exige una asistencia obligatoria y activa & 3.65 & .61 & 3.79 & .48 & 637.500 & .309 \\
\hline $\begin{array}{l}\text { b) Tiene una dinámica de trabajo poco } \\
\text { conocida, falta de hábito }\end{array}$ & 2.65 & 1.59 & 2.61 & 1.54 & 696.000 & .885 \\
\hline
\end{tabular}


Estudios Pedagógicos XLIV, N²: 55-77, 2018 EFECTOS DE LA APLICACIÓN DE UN SISTEMA DE EVALUACIÓN FORMATIVA EN LA AUTOPERCEPCIÓN DE COMPETENCIAS ADQUIRIDAS EN FORMACIÓN INICIAL DEL PROFESORADO

\begin{tabular}{|l|c|c|c|c|c|c|}
\hline c) Exige continuidad & 3.91 & .29 & 3.88 & .33 & 689.500 & .693 \\
\hline d) Hay que comprenderlo previamente & 2.74 & 1.13 & 3.12 & .89 & 517.000 &. $\mathbf{. 0 4 9}$ \\
\hline e) Exige un mayor esfuerzo & 3.53 & .74 & 3.73 & .52 & 625.000 & .271 \\
\hline f) Existe dificultad para trabajar en grupo & 1.84 & 1.46 & 2.36 & 1.08 & 502.500 &. $\mathbf{. 0 2 6}$ \\
\hline g) Se puede acumular mucho trabajo al final & 2.19 & 1.48 & 2.91 & 1.18 & 513.500 &. $\mathbf{. 0 3} *$ \\
\hline h) Existe una desproporción trabajo/créditos & 2.67 & 1.67 & 3.18 & 1.16 & 580.500 & .160 \\
\hline $\begin{array}{l}\text { i) El proceso de calificación es más complejo } \\
\text { y, a veces, poco claro }\end{array}$ & 1.56 & 1.50 & 2.03 & .98 & 520.000 & $\mathbf{. 0 4 2 *}$ \\
\hline $\begin{array}{l}\text { j) Genera inseguridad e incertidumbre, dudas } \\
\text { sobre qué hay que realizar }\end{array}$ & 1.63 & 1.31 & 2.09 & 1.28 & 574.500 & .147 \\
\hline $\begin{array}{l}\text { k) Es injusto frente a otros procesos de } \\
\text { evaluación }\end{array}$ & 1.65 & 1.90 & 1.48 & 1.54 & 691.000 & .841 \\
\hline $\begin{array}{l}\text { 1) Las correcciones han sido poco claras } \\
\text { m) La valoración del trabajo es subjetiva }\end{array}$ & 1.44 & 1.18 & 1.82 & 1.45 & 615.000 & .305 \\
\hline $\begin{array}{l}\text { n) Exige participar en mi propia evaluación } \\
\text { (autoevaluarse) }\end{array}$ & 3.45 & 1.05 & 3.33 & .65 & 611.500 & .336 \\
\hline
\end{tabular}

Nota: U=U de Mann-Whitney; M=Media; dt.= Desviación Típica; * $=\mathrm{p} \leq .05$

Las valoraciones del alumnado (Tabla 3) se agrupan en dos bloques. Por una parte están los ítems con valoración media/alta (2,19-3,91 sobre 4), referentes a exigencias de asistencia, continuidad, comprensión previa, mayor esfuerzo, acumulación de trabajo al finalizar, desproporción de trabajo/créditos, exigencia de autoevaluarse y el tener que comprender previamente el sistema de EFyC empleado. El segundo recoge ítems con una valoración media/baja (1.44-2.36 sobre 4), vinculada a aspectos que interfieren con un correcto proceso de E-A (dificultad para trabajar en grupo, poca claridad del proceso de calificación, incertidumbre que genera y dudas sobre lo que hay que realizar, injusticias frente a otros procesos de evaluación, poca claridad de las correcciones y valoración subjetiva de los trabajos).

En cuatro ítems se observan diferencias significativas entre los grupos, y en todas ellas las valoraciones más elevadas corresponden al alumnado de PECEPI ("Hay que comprenderlo previamente", "Existe dificultad para trabajar en grupo", "Se puede acumular mucho trabajo al final", "El proceso de calificación es más complejo y, a veces, poco claro"),

\subsection{AUTOPERCEPCIÓN DE COMPETENCIA DEL ALUMNADO}

Tras el análisis de los datos obtenidos en la "Escala para la autopercepción de competencia de los estudiantes", pre-test y pos-test, se ordenaron los resultados en tres tablas correspondientes a: "Competencias Transversales", "Competencias Docentes Generales" y "Competencias Docentes Específicas de Educación Física” (tablas 4, 5 y 6). 
Estudios Pedagógicos XLIV, $\mathrm{N}^{\circ}$ 2: 55-77, 2018

EFECTOS DE LA APLICACIÓN DE UN SISTEMA DE EVALUACIÓN FORMATIVA EN LA AUTOPERCEPCIÓN DE COMPETENCIAS ADQUIRIDAS EN FORMACIÓN INICIAL DEL PROFESORADO

Tabla 4. Autopercepción de Competencias Transversales: Medias, dt. y Diferencia de Medias para MGEI y PECEPI Previo y Posterior a la Experiencia de EFyC (* indica diferencias significativas)

\begin{tabular}{|c|c|c|c|c|c|c|}
\hline Ítems & $\begin{array}{c}\text { M/dt. pre-t } \\
\text { MGEI }\end{array}$ & $\begin{array}{c}\text { M/dt. post-t } \\
\text { MGEI }\end{array}$ & $\begin{array}{l}\text { U/Sig. } \\
\text { MGEI }\end{array}$ & $\begin{array}{c}\text { M/dt. pre-t } \\
\text { PECEPI }\end{array}$ & $\begin{array}{l}M / d t \text {. post-t } \\
\text { PECEPI }\end{array}$ & $\begin{array}{l}\text { U/Sig. } \\
\text { PECEPI }\end{array}$ \\
\hline a) Analizar y sintetizar & $3.05 / .39$ & $3.25 / .48$ & 681.000/.05* & $2.97 / .54$ & $2.94 / .58$ & $666.500 / .816$ \\
\hline b) Organizar y planificar & $3.35 / .58$ & $3.43 / .54$ & $761.000 / .567$ & $3.26 / .50$ & $3.39 / .49$ & $605.000 / .303$ \\
\hline $\begin{array}{l}\text { c) Comunicarse de forma } \\
\text { oral y escrita en lengua } \\
\text { nativa }\end{array}$ & $3.11 / .50$ & $2.95 / .71$ & $761.000 / .396$ & $3.16 / .49$ & $2.92 / .60$ & $557.000 / .078$ \\
\hline $\begin{array}{l}\text { d) Comunicarse gestual y } \\
\text { corporalmente }\end{array}$ & $3.03 / .59$ & $3.27 / .69$ & $663.000 / .073$ & $3.16 / .60$ & $3.17 / .50$ & $663.000 / .968$ \\
\hline $\begin{array}{l}\text { e) Conocer una lengua } \\
\text { extranjera }\end{array}$ & $2.21 / .70$ & $1.82 / .62$ & 602.000/.013* & $2.50 / .56$ & $1.56 / .55$ & 198.000/.0* \\
\hline $\begin{array}{l}\text { f) Utilizar las Tecnologías } \\
\text { de la Información y la } \\
\text { comunicación en el } \\
\text { ámbito de estudio }\end{array}$ & $3.13 / .81$ & $2.36 / .83$ & $441.000 / .0 *$ & $3.05 / .76$ & $1.72 / .81$ & $194.000 / .0 *$ \\
\hline g) Trabajar en equipo & $3.66 / .54$ & $3.68 / .47$ & $809.000 / .758$ & $3.45 / .50$ & $3.75 / .55$ & $460.000 / .004 *$ \\
\hline $\begin{array}{l}\text { h) Desarrollar habilidades } \\
\text { en las relaciones } \\
\text { interpersonales (empatía, } \\
\text { asertividad, respeto y } \\
\text { escucha) }\end{array}$ & $3.47 / .60$ & $3.49 / .55$ & $817.000 / .1 .000$ & $3.74 / .44$ & $3.47 / .60$ & $531.000 / .049 *$ \\
\hline $\begin{array}{l}\text { i) Desarrollar habilidades } \\
\text { intrapersonales } \\
\text { (autoestima, motivación y } \\
\text { confianza en uno mismo) }\end{array}$ & $3.16 / .50$ & $3.27 / .66$ & $721.000 / .308$ & $3.26 / .68$ & $3.17 / .69$ & $633.000 / .546$ \\
\hline $\begin{array}{l}\text { j) Razonar de forma } \\
\text { crítica y reflexiva }\end{array}$ & $3.08 / .42$ & $3.36 / .48$ & 614.000/.008* & $3.13 / .62$ & $3.00 / .63$ & $611.500 / .368$ \\
\hline $\begin{array}{l}\text { k) Desarrollar un } \\
\text { compromiso ético }\end{array}$ & $3.03 / .63$ & $2.95 / .71$ & $811.000 / .788$ & $3.24 / .59$ & $2.75 / .69$ & $434.500 / .002 *$ \\
\hline $\begin{array}{l}\text { 1) Desarrollar un } \\
\text { aprendizaje autónomo }\end{array}$ & $3.18 / .51$ & $3.25 / .53$ & $785.000 / .56$ & $3.38 / .54$ & $3.19 / .62$ & $568.000 / .216$ \\
\hline $\begin{array}{l}\text { m) Adaptarse a } \\
\text { situaciones nuevas }\end{array}$ & $3.24 / .59$ & $3.36 / .61$ & $740.500 / .315$ & $3.34 / .53$ & $3.33 / .63$ & $676.500 / .926$ \\
\hline $\begin{array}{l}\text { n) Desarrollar la } \\
\text { creatividad }\end{array}$ & $3.11 / .68$ & $3.25 / .71$ & $739.500 / .328$ & $3.08 / .78$ & $3.17 / .69$ & $639.000 / .597$ \\
\hline $\begin{array}{l}\text { Puntuación global en la } \\
\text { escala (0-56) }\end{array}$ & 43.81 & 43.69 & $791 / .674$ & 44.72 & 41.53 & 418.5/.003* \\
\hline $\begin{array}{l}\text { Puntuación media global } \\
\text { en escala } 0-4\end{array}$ & 3.12 & 3.12 & & 3.19 & 2.97 & \\
\hline
\end{tabular}


Los resultados de la puntuación global de la escala son altos, aunque inferior en el pos-test en las dos titulaciones, pero con diferencias significativas únicamente para el grupo PECEPI. Respecto a las medias de cada ítem, el alumnado de MGEI muestra valores altos o muy altos en la mayoría de los ítems. Además, en once competencias el alumnado tiene una valoración más elevada en el post-test, aunque solamente en dos las diferencias son estadísticamente significativas ("analizar y sintetizar" y "razonar de forma crítica y reflexiva"). En cambio, en cuatro competencias los valores del pos-test son inferiores del pre-test, y en dos la diferencia es significativa ("conocer una lengua extranjera" y "utilizar las tecnologías de la Información y la comunicación en el ámbito de estudio"). Para la titulación PECEPI podemos ver valores altos o muy altos en la mayoría de las competencias, pero varían de forma muy diferente. En cuatro competencias la valoración del pos-test es más alta (b, d, g, n) y una de ellas es significativa ("trabajar en equipo"). En cambio, en diez competencias la valoración final es más baja (a, c, e, f, h, i, j, k, l, m), de las cuales cuatro muestran diferencias significativas ("conocer una lengua extranjera", "utilizar las tecnologías de la información y la comunicación en el ámbito de estudio", "desarrollar habilidades en las relaciones interpersonales" y "desarrollar un compromiso ético").

En la Tabla 5 se presentan los resultados para los ítems referidos a las competencias docentes generales.

Tabla 5. Autopercepción de Competencias docentes generales: Medias, dt. y diferencia de Medias para MGEI y PECEPI previo y posterior a la experiencia de EFyC (* indica diferencias significativas)

\begin{tabular}{|l|c|c|c|c|c|c|}
\hline Ítems & $\begin{array}{c}\text { M/dt. pre-t } \\
\text { MGEI }\end{array}$ & $\begin{array}{c}\text { M/dt. post-t } \\
\text { MGEI }\end{array}$ & $\begin{array}{c}\text { U/Sig. } \\
\text { MGEI }\end{array}$ & $\begin{array}{c}\text { M/dt. pre-t } \\
\text { PECEPI }\end{array}$ & $\begin{array}{c}\text { M/dt. post-t } \\
\text { PECEPI }\end{array}$ & $\begin{array}{c}\text { U/Sig. } \\
\text { PECEPI }\end{array}$ \\
\hline $\begin{array}{l}\text { a) Conocer las } \\
\text { características } \\
\text { organizativas de los } \\
\text { centros educativos }\end{array}$ & $2.63 / .53$ & $2.45 / .62$ & $716.000 / .211$ & $2.68 / .62$ & $2.33 / .63$ & $495.000 / .022^{*}$ \\
\hline $\begin{array}{l}\text { b) Elaborar propuestas } \\
\text { de cambio de la } \\
\text { realidad educativa }\end{array}$ & $2.68 / .47$ & $3.11 / .61$ & $548.000 / .002^{*}$ & $2.34 / .62$ & $2.75 / .77$ & $453.000 / .006 *$ \\
\hline $\begin{array}{l}\text { c) Diseñar situaciones } \\
\text { de aprendizaje }\end{array}$ & $3.03 / .49$ & $3.48 / .54$ & $500.500 / .0^{*}$ & $2.66 / .66$ & $3.36 / .63$ & $318.000 / . \mathbf{0}^{*}$ \\
\hline $\begin{array}{l}\text { d) Animar situaciones } \\
\text { de aprendizaje }\end{array}$ & $3.08 / .48$ & $3.43 / .58$ & $566.500 / .004 *$ & $3.00 / .65$ & $3.17 / 60$ & $583.000 / .201$ \\
\hline $\begin{array}{l}\text { e) Gestionar la } \\
\text { progresión de los } \\
\text { aprendizajes }\end{array}$ & $3.00 / .61$ & $3.18 / .54$ & $712.000 / .169$ & $2.55 / .68$ & $3.03 / .65$ & $439.000 / .004 *$ \\
\hline $\begin{array}{l}\text { f) Diseñar estrategias de } \\
\text { atención a la diversidad }\end{array}$ & $2.71 / .61$ & $3.30 / .67$ & $452.000 / .0^{*}$ & $2.79 / .66$ & $3.22 / .72$ & $464.000 / .01 *$ \\
\hline $\begin{array}{l}\text { g) Poner en práctica } \\
\text { estrategias de atención } \\
\text { a la diversidad }\end{array}$ & $2.63 / .58$ & $2.98 / .73$ & $623.000 / .03^{*}$ & $2.87 / .66$ & $2.58 / .93$ & $551.500 / .123$ \\
\hline
\end{tabular}


Estudios Pedagógicos XLIV, N $^{\circ}$ 2: 55-77, 2018

EFECTOS DE LA APLICACIÓN DE UN SISTEMA DE EVALUACIÓN FORMATIVA EN LA AUTOPERCEPCIÓN DE COMPETENCIAS ADQUIRIDAS EN FORMACIÓN INICIAL DEL PROFESORADO

\begin{tabular}{|c|c|c|c|c|c|c|}
\hline $\begin{array}{l}\text { h) Implicar al } \\
\text { alumnado en su } \\
\text { aprendizaje }\end{array}$ & $3.21 / .57$ & $3.36 / .53$ & $699.500 / .267$ & $3.11 / .50$ & $3.17 / .69$ & $627.000 / .46$ \\
\hline $\begin{array}{l}\text { i) Implicar al alumnado } \\
\text { en la vida del centro }\end{array}$ & $2.76 / .59$ & $2.61 / .81$ & $728.000 / .273$ & $2.95 / .65$ & $2.47 / .81$ & $455.500 / .006 *$ \\
\hline $\begin{array}{l}\text { j) Participar en la } \\
\text { gestión del Centro }\end{array}$ & $2.53 / .64$ & $2.12 / .62$ & $550.000 / .005^{*}$ & $2.70 / .77$ & $1.92 / .64$ & $315.000 / .0 *$ \\
\hline $\begin{array}{l}\text { k) Informar a las } \\
\text { familias sobre la } \\
\text { evolución de su hijo/a }\end{array}$ & $2.92 / .78$ & $2.05 / .68$ & $357.000 / .0 *$ & $3.08 / .85$ & $1.72 / .61$ & $162.500 / .0 *$ \\
\hline $\begin{array}{l}\text { 1) Implicar a las } \\
\text { familias en el } \\
\text { aprendizaje de su hijo/a }\end{array}$ & $3.11 / .72$ & $2.14 / .79$ & $332.000 / .0 *$ & $2.97 / .82$ & $1.83 / .69$ & $222.000 / .0 *$ \\
\hline $\begin{array}{l}\text { m) Implicar a las } \\
\text { familias en la vida del } \\
\text { centro }\end{array}$ & $3.05 / .69$ & $2.02 / .82$ & $312.000 / .0 *$ & $2.59 / .76$ & $1.67 / .58$ & $250.000 / .0 *$ \\
\hline $\begin{array}{l}\text { n) Afrontar los deberes } \\
\text { y dilemas éticos de la } \\
\text { profesión }\end{array}$ & $3.03 / .60$ & $2.64 / .78$ & $590.500 / .018 *$ & $2.86 / .59$ & $2.75 / .73$ & $621.000 / .719$ \\
\hline $\begin{array}{l}\text { o) Atender al propio } \\
\text { desarrollo profesional } \\
\text { docente } \\
\text { (autoevaluación, } \\
\text { lecturas, cursos, } \\
\text { jornadas, congresos, } \\
\text { redes de trabajo) }\end{array}$ & $3.03 / .59$ & $3.39 / .72$ & $559.000 / .004 *$ & $2.89 / .68$ & $3.17 / .66$ & $518.500 / .062$ \\
\hline $\begin{array}{l}\text { p) Desarrollar procesos } \\
\text { de innovación educativa } \\
\text { en el aula }\end{array}$ & $3.16 / .43$ & $3.20 / .73$ & $753.500 / .352$ & $2.71 / .73$ & $3.14 / .72$ & 471.000/.011* \\
\hline $\begin{array}{l}\text { q) Poner en marcha } \\
\text { procesos de } \\
\text { investigación en el aula }\end{array}$ & $2,66 / .74$ & $2.59 / .78$ & $806.000 / .761$ & $2.58 / .75$ & $2.44 / .73$ & $612.000 / .396$ \\
\hline $\begin{array}{l}\text { Puntuación global en la } \\
\text { escala }(0-68)\end{array}$ & 49.22 & 48.05 & 781.5/.611 & 47.33 & 44.72 & $\begin{array}{c}598.5 / \\
.353\end{array}$ \\
\hline $\begin{array}{l}\text { Puntuación global en } \\
\text { escala 0-4 }\end{array}$ & 2.90 & 2.82 & & 2.78 & 2.63 & \\
\hline
\end{tabular}

Nota: U=U de Mann-Whitney; M=Media; dt.= Desviación Típica; * $=\mathrm{p} \leq .05$

La puntuación global en la escala es alta, aunque más bajos en el pos-test en los dos grupos, sin diferencias estadísticamente significativas. Respecto a las medias en cada ítem, el alumnado de MGEI muestra valores altos en la mayoría de los ítems y medios en algunos casos; además, en nueve competencias la valoración es más elevada en el pos-test, aunque solamente en seis las diferencias son significativas ("elaborar propuestas de cambio 
de la realidad educativa", "diseñar situaciones de aprendizaje", "animar situaciones de aprendizaje", "diseñar estrategias de atención a la diversidad", "poner en práctica estrategias de atención a la diversidad", "Atender al propio desarrollo profesional docente").

En cambio, en ocho competencias los valores del pos-test son inferiores y en cinco la diferencia es significativa ("participar en la gestión del centro", "informar a las familias sobre la evolución de su hijo/a", "implicar a las familias en el aprendizaje de su hijo/a", "implicar a las familias en la vida del centro" y "afrontar los deberes y dilemas éticos de la profesión").

Para la titulación PECEPI podemos encontrar valores medios y altos en la mayoría de las competencias, por lo general ligeramente inferiores a los del alumnado de la otra titulación. Las diferencias son similares respecto al otro grupo. En ocho competencias el alumnado otorga una valoración más alta finalizada la asignatura, pero solamente cinco son significativas ("elaborar propuestas de cambio de la realidad educativa", "diseñar situaciones de aprendizaje", "gestionar la progresión de los aprendizajes", "diseñar estrategias de atención a la diversidad", "desarrollar procesos de innovación educativa en el aula"). En nueve competencias la valoración final es más baja, pero únicamente seis muestran diferencias significativas ("conocer las características organizativas de los centros educativos", "implicar al alumnado en la vida del centro", "participar en la gestión del centro", "informar a las familias sobre la evolución de su hijo/a", "implicar a las familias en el aprendizaje de su hijo/a", "implicar a las familias en la vida del centro").

En la Tabla 6 se presentan las medias, desviación típica y diferencia de medias para las competencias específicas docentes de Educación Física.

Tabla 6. Autopercepción de Competencias específicas docentes de Educación Física: Medias, dt. y diferencia de Medias para MGEI y PECEPI previo y posterior a la experiencia de EFyC (* indica diferencias significativas)

\begin{tabular}{|l|c|c|c|c|c|c|}
\hline Ítems & $\begin{array}{c}\text { M/dt. pre-t } \\
\text { MGEI }\end{array}$ & $\begin{array}{c}\text { M/dt. post-t } \\
\text { MGEI }\end{array}$ & $\begin{array}{c}\text { U/Sig. } \\
\text { MGEI }\end{array}$ & $\begin{array}{c}\text { M/dt. pre-t } \\
\text { PECEPI }\end{array}$ & $\begin{array}{c}\text { M/dt. post-t } \\
\text { PECEPI }\end{array}$ & $\begin{array}{c}\text { U/Sig. } \\
\text { PECEPI }\end{array}$ \\
\hline $\begin{array}{l}\text { a) Diseñar, aplicar y } \\
\text { analizar intervenciones } \\
\text { didácticas en el área de } \\
\text { Educación Física }\end{array}$ & $2.55 / .50$ & $3.52 / .50$ & $220.500 / .0^{*}$ & $2.71 / .69$ & $3.39 / .68$ & $340.000 / .0^{*}$ \\
\hline $\begin{array}{l}\text { b) Diseñar, desarrollar } \\
\text { y evaluar los procesos } \\
\text { de E-R relativos a la } \\
\text { actividad física y el } \\
\text { deporte con atención a } \\
\text { las Necesidades } \\
\begin{array}{l}\text { Específicas de Apoyo } \\
\text { Educativo }\end{array}\end{array}$ & $2.53 / .55$ & $3.32 / .60$ & $339.000 / .0^{*}$ & $2.66 / .74$ & $3.19 / .66$ & $415.000 / .001 *$ \\
\hline $\begin{array}{l}\text { c) Conocer y promover } \\
\text { las diferentes } \\
\text { manifestaciones } \\
\text { motrices que forman } \\
\text { parte de la cultura } \\
\text { tradicional }\end{array}$ & $2.66 / .70$ & $3.14 / .59$ & $533.500 / .002 *$ & $2.66 / .62$ & $3.14 / .86$ & $434.500 / .004 *$ \\
\hline
\end{tabular}


Estudios Pedagógicos XLIV, N$^{\circ}$ 2: 55-77, 2018

EFECTOS DE LA APLICACIÓN DE UN SISTEMA DE EVALUACIÓN FORMATIVA EN LA AUTOPERCEPCIÓN DE COMPETENCIAS ADQUIRIDAS EN FORMACIÓN INICIAL DEL PROFESORADO

\begin{tabular}{|c|c|c|c|c|c|c|}
\hline $\begin{array}{l}\text { d) Conocer y aplicar los } \\
\text { fundamentos } \\
\text { biológicos, fisiológicos, } \\
\text { de maduración } \\
\text { evolutiva y el desarrollo } \\
\text { psicomotor }\end{array}$ & $2.71 / .61$ & $3.30 / .59$ & $454.500 / .0 *$ & $2.34 / .70$ & $3.06 / .67$ & $317.500 / .0^{*}$ \\
\hline $\begin{array}{l}\text { e) Diseñar, modificar } \\
\text { y/o adaptar al contexto } \\
\text { educativo situaciones } \\
\text { motrices orientadas al } \\
\text { desarrollo y } \\
\text { perfeccionamiento de } \\
\text { las habilidades motrices }\end{array}$ & $2.79 / .52$ & $3.36 / .53$ & $440.000 / .0 *$ & $2.58 / .72$ & $3.25 / .60$ & $349.500 / .0 *$ \\
\hline $\begin{array}{l}\text { f) Conocer los } \\
\text { elementos y } \\
\text { fundamentos de la } \\
\text { expresión corporal y la } \\
\text { comunicación no verbal } \\
\text { y su valor formativo y } \\
\text { cultural }\end{array}$ & $2.82 / .56$ & $3.42 / .54$ & $418.000 / .0 *$ & $2.89 / .62$ & $3.22 / .79$ & 471.000/.029* \\
\hline $\begin{array}{l}\text { g) Saber utilizar el } \\
\text { juego como recurso } \\
\text { didáctico y como } \\
\text { contenido de enseñanza }\end{array}$ & $3.58 / .50$ & $3.70 / .50$ & 720.000/.19 & $3.42 / .64$ & $3.64 / .65$ & $561.500 / .127$ \\
\hline $\begin{array}{l}\text { h) Conocer los } \\
\text { fundamentos básicos de } \\
\text { la iniciación deportiva } \\
\text { escolar y diseñar tareas } \\
\text { específicas para } \\
\text { utilizarlos en el ámbito } \\
\text { de la enseñanza }\end{array}$ & $2.79 / .57$ & $3.34 / .56$ & $465.500 / .0 *$ & $2.84 / .78$ & $3.25 / .55$ & 485.500/.018* \\
\hline $\begin{array}{l}\text { i) Identificar los riesgos } \\
\text { que se derivan para la } \\
\text { salud de la práctica de } \\
\text { actividades físicas } \\
\text { inadecuadas }\end{array}$ & $2.76 / .71$ & $2.77 / .80$ & $829.000 / .944$ & $2.82 / .69$ & $2.50 / .60$ & $525.000 / .052$ \\
\hline $\begin{array}{l}\text { j) Diseñar un plan de } \\
\text { hábitos de vida } \\
\text { saludable (higiene y } \\
\text { alimentación) y de } \\
\text { práctica de actividad } \\
\text { física regular }\end{array}$ & $3.08 / .63$ & $2.64 / .71$ & $547.000 / .003 *$ & $3.18 / .69$ & $2.47 / .65$ & $316.000 / .0 *$ \\
\hline $\begin{array}{l}\text { k) Saber aplicar los } \\
\text { fundamentos (técnicas) } \\
\text { de las actividades } \\
\text { físicas en el medio } \\
\text { natural }\end{array}$ & $2.68 / .52$ & $2.77 / .77$ & 793.000/.657 & $3.03 / .67$ & $2.56 / .80$ & 487.500/.018* \\
\hline $\begin{array}{l}\text { 1) Saber utilizar } \\
\text { diferentes instrumentos } \\
\text { de evaluación en el área } \\
\text { de Educación Física }\end{array}$ & $2.76 / .59$ & $3.39 / .57$ & $426.000 / .0 *$ & $2.87 / .66$ & $3.25 / .60$ & 480.000/.013* \\
\hline
\end{tabular}




\begin{tabular}{|c|c|c|c|c|c|c|}
\hline $\begin{array}{l}\text { m) Tener capacidad de } \\
\text { reflexión sobre el } \\
\text { proceso de enseñanza/ } \\
\text { aprendizaje y las } \\
\text { distintas metodologías } \\
\text { dentro de las clases de } \\
\text { Educación Física }\end{array}$ & $2.84 / .59$ & $3.55 / .50$ & $368.000 / .0 *$ & $2.82 / .65$ & $3.36 / .54$ & $396.500 / .0 *$ \\
\hline $\begin{array}{l}\text { n) Analizar y } \\
\text { comunicar, de manera } \\
\text { crítica y fundamentada, } \\
\text { el valor de la actividad } \\
\text { física y el deporte y sus } \\
\text { posibilidades de } \\
\text { contribuir al desarrollo } \\
\text { y bienestar de las } \\
\text { personas }\end{array}$ & $2.95 / .46$ & $3.41 / .58$ & 497.000/.0* & $2.95 / .73$ & $3.39 / .59$ & 463.000/.007* \\
\hline $\begin{array}{l}\text { Puntuación global en la } \\
\text { escala (0-56) }\end{array}$ & 39.5 & 45.63 & $312 / .0001 *$ & 39.77 & 43.67 & 410/ .002* \\
\hline $\begin{array}{l}\text { Puntuación global en } \\
\text { escala 0-4 }\end{array}$ & 2.82 & 3.25 & & 2.84 & 3.12 & \\
\hline
\end{tabular}

Nota: U=U de Mann-Whitney; M=Media; dt.= Desviación Típica; *=p $\leq .05$

La puntuación global en la escala es alta y significativamente más alta el pos-test en los dos grupos, con diferencias más altas en la titulación MGEI que en PECEPI. Respecto a las medias en cada ítem, el alumnado de la titulación MGEI muestra valores entre altos y muy altos en la mayoría de los ítems (entre 2.53-3.70). Además, en trece de las catorce competencias el alumnado tiene una valoración más elevada en el pos-test, y en diez de ellas las diferencias son estadísticamente significativas (a, b, c, d, e, f, h, l, m, n). En cambio, solamente en una competencia los valores del pos-test son inferiores del pre-test, y la diferencia es significativa ("diseñar un plan de hábitos de vida saludable (higiene y alimentación) y de práctica de actividad física regular"). Por su parte, la titulación PECEPI también muestra valores altos o muy altos en la mayoría de las competencias (entre 2.34-3.64 en la escala de 1-4). En diez de las catorce competencias el alumnado otorga una valoración más alta finalizada la asignatura, todas significativas ( $a, b, c, d, e, f, h, 1, m, n$ ). En cambio, en tres competencias la valoración final es más baja, de las cuales solamente dos muestran diferencias significativas ("diseñar un plan de hábitos de vida saludable y de práctica de actividad física regular" y "saber aplicar los fundamentos de las actividades físicas en el medio natural").

Si comparamos las puntuaciones globales en las tres escalas, se pueden comprobar varios resultados: (a) En los dos grupos, las puntuaciones más altas en el pos-test se corresponden siempre a la autopercepción de competencia docente específica en EF; en segundo lugar las competencias transversales y en tercer lugar las competencias docentes generales; (b) en los dos grupos, las puntuaciones solamente son más altas en el pos-test en la escala de autopercepción de competencia docente específica en EF, en los dos casos con diferencias significativas; (c) en los dos grupos, en las otras dos escalas las puntuaciones del pos-test son inferiores en tres casos, aunque estas diferencias solamente son significativas en una de las tres posibilidades. 


\section{DISCUSIÓN}

El primer objetivo del estudio se centraba en analizar la valoración que el alumnado de dos titulaciones (MGEI y PECEPI) realiza sobre una asignatura que utiliza un sistema de EFyC en FIP. En este sentido, los resultados muestran una elevada satisfacción del alumnado con el sistema de EFyC vivido, con valoraciones altas en ventajas y bajas en inconvenientes, tanto para MGEI y PECEPI, lo que está en línea con estudios recientes sobre estos sistemas de evaluación (Atienza et al., 2016; Delgado et al., 2016; Romero-Martín et al., 2017), así como con la recopilación que se hace sobre sistemas de EFyC en todas las etapas formativas (López-Pastor \& Pérez-Pueyo, 2017) y con estudios que han incluido muestras numerosas de universidades españolas (Manrique-Arribas et al., 2012; Hortigüela-Alcalá, Pérez-Pueyo \& López-Pastor, 2015), también con experiencias implementadas en otros contextos universitarios, como el chileno (Gallardo \& Carter, 2016).

A pesar de que ambos grupos otorgan altas valoraciones, hay tres ítems con diferencias significativas entre grupos, en todos los casos con valoraciones más altas para MGEI, que es dos cursos más avanzado. Estos resultados presentan concordancia con estudios que han encontrado una mayor implicación del alumnado de cursos superiores hacia los sistemas de EFyC (Buscá, Rivera \& Trigueros, 2012; Hortigüela-Alcalá et al., 2015).

En los ítems referentes a las "posibles desventajas del sistema de evaluación", las valoraciones se dividieron en dos grupos: (a) las afirmaciones que muestran una valoración media/alta, se refirieren a la asistencia, continuidad, comprensión previa, mayor esfuerzo, acumulación de trabajo al finalizar, desproporción de trabajo/créditos, exigencia de autoevaluarse y el tener que comprender previamente el sistema de EFyC empleado. En este sentido, López-Pastor $(2009,2012)$ considera que más que desventajas deberían considerarse características propias de los sistemas de EFyC; (b) otro bloque de ítems obtuvieron una valoración media/baja o muy baja: "Tiene una dinámica de trabajo poco conocida, falta de hábito", "Existe dificultad para trabajar en grupo", "El proceso de calificación es más complejo y, a veces, poco claro", "Genera inseguridad e incertidumbre, dudas sobre qué hay que realizar", "Es injusto frente a otros procesos de evaluación", "Las correcciones han sido poco claras", "La valoración del trabajo es subjetiva". Estos datos muestran una alta implicación del alumnado con el sistema de EFyC utilizado y una buena comprensión del mismo; resultados similares a los encontrados por Romero-Martín, Castejón-Oliva y López-Pastor (2015). En cambio, en otros estudios se pueden encontrar ciertas diferencias en estos últimos aspectos (Gallardo \& Carter, 2016; Manrique-Arribas et al., 2012), fundamentalmente por resistencias del alumnado en sus primeras experiencias con estos tipos de metodologías evaluativas. También hay casos que muestran cómo la implicación del alumnado se relaciona con el curso en el que está matriculado, y son los cursos superiores donde hay mayor implicación (HortigüelaAlcalá et al., 2015). Esto último también puede observarse en las diferencias de medias significativas en cuatro ítems ("Hay que comprenderlo previamente", "Existe dificultad para trabajar en grupo", "Se puede acumular mucho trabajo al final", "El proceso de calificación es más complejo y, a veces, poco claro"), donde el alumnado de primer curso (PECEPI) siempre muestra puntuaciones superiores. Estos resultados están en la misma línea de los resultados encontrados en el apartado de "ventajas", en lo relativo a que alumnado de cursos más avanzados valoran de forma más positiva la utilización de sistemas de EFyC (Buscá \& Trigueros, 2012; Hortigüela-Alcalá et al., 2015), mientras el 
alumnado de cursos iniciales presenta mayor dificultad para comprender y aprovechar los sistemas de EFyC.

El segundo objetivo del estudio es analizar la autopercepción del alumnado de las dos titulaciones sobre las competencias profesionales adquiridas durante una asignatura que utiliza un sistema de EFyC en FIP. Tanto en las puntuaciones globales por escalas como en el análisis por ítems se observan numerosas diferencias significativas entre pre-test vs. pos-test.

Los resultados de la puntuación global de la escala de autopercepción de competencias transversales son altos, pero con diferencias significativas solamente para el grupo PECEPI. En cuanto a los diferentes ítems, para MGEI se encontraron valores altos y muy altos en el pos-test en once competencias, en algunas de ellas con diferencias significativas. Estos resultados son paradójicos. Por un lado, los valores globales parecen empeorar la autopercepción de competencias transversales, aunque las diferencias solo son significativas con el grupo PECEPI; mientras que por otro lado, algunas competencias concretas sí aumentan significativamente en el pos-test. En Manrique-Arribas et al. (2012), en un estudio que analiza 29 casos de EFyC, con una muestra de 1.770 alumnos, encuentran mejoras en la percepción de adquisición de competencias transversales específicas cuando se utilizan sistemas de EFyC, especialmente en las competencias de "aprendizaje autónomo". Por su parte, Alonso-Martin (2010) encontró altas valoraciones en la competencia de "Razonamiento crítico" al finalizar una asignatura de la carrera de psicología en una universidad española. Por otra parte, en el grupo MGEI destacan dos competencias con diferencias significativas más bajas en el pos-test ("conocer una lengua extranjera" y "utilizar las tecnologías de la Información y la comunicación en el ámbito de estudio"), lo cual choca con el estudio de Sánchez, Mirete, García y Hernández (2013), en donde el $91 \%$ de los participantes considera como necesarias o muy necesarias las TICS en las situaciones de aprendizaje. Además, es especialmente preocupante que sean las puntuaciones más bajas de toda la escala, en la situación mundial actual, metidos de lleno en una era digital y con una clara necesidad de dominar al menos una segunda lengua. La explicación de por qué la autopercepción de competencia baja al final de cuatrimestre puede deberse a que realmente se trata de dos competencias muy poco utilizadas durante la asignatura, dado que solamente se utiliza la segunda lengua (inglés) en una sesión práctica y únicamente se utilizan las nuevas tecnologías (TIC) para la elaboración de los documentos y trabajos. Por tanto, es normal que la puntuación sea muy baja cuando se les pregunta en qué medida esta asignatura les ha ayudado a desarrollar dichas competencias. En este sentido, coincide con lo encontrado en un estudio similar con una muestra mucho más grande en FIP (1.243 alumnos de 24 universidades españolas) (Romero-Martín et al., 2017). En lo que respecta al grupo de PECEPI, las únicas diferencias significativas, más altas en el pos-test se dan en la competencia: "trabajar en equipo". Se trata de un resultado lógico, dado que la organización de la asignatura implica mucho tiempo de trabajo en grupos colaborativos. Pueden encontrarse resultados similares en estudios sobre el uso de sistemas de EFyC basados en el trabajo colaborativo y los proyectos de aprendizaje (Atienza et al., 2016; Hortigüela, Pérez-Pueyo \& Abella, 2015; Martínez-Mínguez, 2016).

La puntuación global en la escala de autopercepción de competencias docentes generales es alta, aunque más bajos en el pos-test en los dos grupos, sin diferencias estadísticamente significativas. Respecto a los ítems, los resultados muestran valores altos y medios en la mayoría de las competencias en los dos grupos. Los resultados vuelven a 
ser paradójicos. Por un lado, los valores globales parecen empeorar la autopercepción de competencias docentes generales, aunque las diferencias no son significativas en ninguno de los dos grupos; mientras que, por otro lado, algunas competencias concretas sí aumentan significativamente en el pos-test, destacando seis competencias para MGEI y cinco para PECEPI. Estos resultados coinciden con otros estudios que utilizaran EFyC, que encuentran que dicho sistema de evaluación ayuda en la adquisición de competencias docentes generales (Santos-Pastor, Martínez-Muñoz \& López-Pastor, 2009; Ureña-Ortín \& Ruiz-Lara, 2012). También hay estudios en los que el alumnado relaciona la utilización de sistemas de EFyC con una mayor adquisición de competencias docentes (Silva \& López-Pastor, 2015). Por otra parte, Dochy, Segers y Dierick (2002) y Dochy, Segers y Sluijsmans (1999) sitúan a la EFyC como responsable de una mayor implicación del alumnado en sus propios procesos de E-A, lo que repercutiría en una mejor adquisición de competencias profesionales. Las competencias que obtuvieron valoraciones bajas en los dos grupos se relacionaban con aspectos como: "Implicar al alumnado en la vida del centro", "Participar en la gestión del centro educativo", "Informar a las familias sobre la evolución de su hijo/a", "Implicar a las familias en el aprendizaje de su hijo/a", "Implicar a las familias en la vida del centro". Se trata de competencias docentes que se trabajan poco a lo largo de esta asignatura, sino que son propias de otras asignaturas de la carrera. Por tanto, se entiende que son resultados coherentes y lógicos.

La puntuación global en la escala de autopercepción de competencias docentes específicas de EF es alta y significativamente más alta el pos-test en los dos grupos, con diferencias más altas en la titulación MGEI que en PECEPI. Respecto a las medias en cada ítem, los resultados ofrecen valores altos y medios en los dos grupos. Además, en 10 ítems de cada grupo, las diferencias en el pos-test son significativas y positivas. Se trata de un resultado lógico, dado que se trata de una asignatura centrada en dotar al alumnado de conocimientos y competencias para el trabajo de la Educación Física en Educación Infantil. En los dos grupos se trata de la única asignatura de la carrera que hasta el momento habían cursado sobre contenidos ligados a la Educación Física. Resultados similares pueden encontrarse en un estudio con alumnado de FIP en Educación Infantil (Barba \& LópezPastor, 2017). Solamente una competencia obtuvo diferencias significativas inferiores en el pos-test en los dos grupos ("diseñar un plan de hábitos de vida saludable y de práctica de actividad física regular"), y una más solamente en el grupo de PECEPI ("saber aplicar los fundamentos de las actividades físicas en el medio natural"). Al igual que anteriores ítems, se trata de resultados lógicos, al ser competencias muy específicas que no se trabajan en esta asignatura, sino que pertenecen a otras asignaturas de cursos posteriores $\mathrm{y}$, especialmente, en él la mención de Educación Física, dentro del grado de Educación Primaria. Pero también se encuentran diferencias entre los dos grupos en algunos ítems ("identificar los riesgos que se derivan para la salud de la práctica de actividades físicas inadecuadas", "saber aplicar los fundamentos (técnicas) de las actividades físicas en el medio natural”). En Silva y LópezPastor (2015), estudio llevado a cabo en FIP en Educación Infantil, el alumnado valora positivamente los sistemas de evaluación y las propuestas de aprendizaje utilizadas a la hora de desarrollar competencias profesionales.

Los resultados de comparar las puntuaciones globales en las tres escalas muestran que, en los dos grupos, las puntuaciones más altas en el pos-test se corresponden siempre a la autopercepción de competencia docente específica en EF; también es la única escala que muestra puntuaciones más altas en el pos-test. Entendemos que se trata de un resultado 
lógico y coherente, dado que es una asignatura específica de Educación Física en Educación Infantil, y la primera de este tipo que reciben los dos grupos. Por tanto, se puede interpretar que el tipo de contenido y competencia trabajada en la asignatura influye más en el desarrollo de las mismas que la mera aplicación de sistemas de EFyC. Resultados similares pueden encontrarse en Fraile-Aranda y otros (2018).

\section{CONCLUSIONES}

Los resultados muestran que el alumnado de los dos grupos considera que los sistemas de EFyC presentan considerables ventajas. Aparecen pocos ítems en que el alumnado manifieste la existencia de "desventajas", que se refirieron principalmente a aspectos como la continuidad en la asistencia, comprensión previa del sistema de evaluación, mayor esfuerzo, etc., que más bien deberían considerarse características propias de todo sistema de EFyC.

Con respecto a la autopercepción de competencias profesionales adquiridas durante una asignatura que utiliza un sistema de EFyC en FIP, los resultados indican valores elevados en la tres escalas de competencias ("Transversales", "Docentes Generales" y "Docentes Específicas de Educación Física"), con excepciones en algunas competencias muy concretas dentro cada una de las escalas y que, por las características propias de la asignatura, realmente han sido muy poco o nada trabajadas durante el desarrollo de la misma. También indican claramente que la única escala que muestra puntuaciones más altas en el pos-test es la de autopercepción de competencia docente específica en EF, que a su vez es la escala que obtiene puntuaciones más altas en la escala global.

Las limitaciones de este estudio responden principalmente al reducido tamaño de la muestra y al tratarse de un estudio muy contextualizado. Sería conveniente realizar futuros estudios sobre la temática con muestras más amplias.

Este artículo puede ser de interés en las universidades que forman por competencias, especialmente a las carreras de FIP. Parecen existir pocos estudios sobre la autopercepción del alumnado en la adquisición de competencias en FIP, por lo que esta investigación puede ser un punto de partida para futuros estudios sobre esta temática, así como apoyar procesos de innovación e investigación-acción en el aula sobre el desarrollo de sistemas de EFyC en FIP. Como prospectiva, sería interesante profundizar en las relaciones que parecen existir entre la utilización de sistemas de EFyC y la adquisición de las competencias más relevantes para el ejercicio docente. Otra posible línea de investigación sería indagar más a fondo sobre el efecto de la aplicación de sistemas de EFyC en titulaciones distintas a MGEI y PECEPI.

\section{REFERENCIAS BIBLIOGRÁFICAS}

Alonso-Martín, P. (2010). La valoración de la importancia de las competencias transversales: comparación de su percepción al inicio y final de curso en alumnos de psicología. Revista de investigación educativa, 28(1), 119-140. Recuperado de http://revistas.um.es/rie/article/ view/97821

Aparicio, J., \& Fraile-Aranda, A. (2015). La evaluación de competencias interpersonales en la 
Estudios Pedagógicos XLIV, $\mathrm{N}^{\circ}$ 2: 55-77, 2018

EFECTOS DE LA APLICACIÓN DE UN SISTEMA DE EVALUACIÓN FORMATIVA EN LA AUTOPERCEPCIÓN DE COMPETENCIAS ADQUIRIDAS EN FORMACIÓN INICIAL DEL PROFESORADO

formación del profesorado de educación física a través de un programa de expresión corporal. International Journal for 21st Century Education, 2(2), 21-34.

Atienza, R., Valencia-Peris, A., Martos-García, D., López-Pastor, V., \& Devís-Devís, J. (2016). La percepción del alumnado universitario de educación física sobre la evaluación formativa: ventajas, dificultades y satisfacción. Movimento, 22(4), 1033-1048. Recuperado de http://www. redalyc.org/html/1153/115349439002/

Barba-Martín, R., \& López-Pastor, V. (2017). Evaluación formativa y compartida en los proyectos de trabajo tutorado, un ejemplo de buena práctica. Revista Infancia, Educación y Aprendizaje, $3(2), 66-70$.

Barba-Martín, J., López-Pastor, V., Manrique-Arribas, J., Gea-Fernández, J., \& Monjas-Aguado, R. (2010). Garantir l'èxit en la formació inicial del professorat d'educació física: els projectes d'aprenentatge tutelats. Temps d'educació, 39, 187-206. Recuperado de http://www.raco.cat/ index.php/TempsEducacio/article/view/245016/328172

Benito, A., \& Cruz, A. (2003). Nuevas claves para la docencia universitaria en el Espacio Europeo de Educación Superior. Madrid: Narcea.

Biggs, J. (2005). Calidad del aprendizaje universitario. Madrid: Narcea.

Bozu, Z., \& Canto, P. (2009). El profesorado universitario en la sociedad del conocimiento: competencias profesionales docentes. Revista de formación e innovación educativa universitaria, 2(2), 87-97. Recuperado de http://tecnologiaedu.us.es/mec2011/htm/mas/3/31/26.pdf

Buscá, F., Rivera, E., \& Trigueros, C. (2012). La credibilitat dels sistemes d'avaluació formativa en la formació inicial del professorat d'educació física. Temps d'Educació, 43, 167-184. Recuperado de http://diposit.ub.edu/dspace/handle/2445/113262

Castejón-Oliva, F., López-Pastor, V., Julián, J., \& Zaragoza, J. (2011). Evaluación formativa y rendimiento académico en la formación inicial del profesorado de Educación Física. Revista Internacional de Medicina y Ciencias de la Actividad Física y del Deporte/International Journal of Medicine and Science of Physical Activity and Sport, 11(42), 328-346. Recuperado de http:// www.redalyc.org/html/542/54222171007/

Castejón-Oliva, F., Santos-Pastor, M., \& Palacios, A. (2015). Cuestionario sobre metodología y evaluación en formación inicial en educación física. Revista Internacional de Medicina y Ciencias de la Actividad Física y del Deporte, 15(58), 245-267. Recuperado de http://cdeporte. rediris.es/revista/revista58/artescala566.htm

De Miguel, M. (2005). Cambio de paradigma metodológico en la Educación Superior. Exigencias que conlleva. Cuadernos de integración europea, 2, 16-27.

Delgado, V., Ausin, V., Hortigüela-Alcalá, D., \& Abella-García, V. (2016). Evaluación entre iguales: Una experiencia de evaluación compartida en Educación Superior. EDUCADI, 1(1). Recuperado de http://cuhso.cl/index.php/educadi/article/view/943

Dochy, F., Segers, M., \& Dierick, S. (2002). Nuevas vías de aprendizaje y enseñanza y sus consecuencias: una era de evaluación. Red Estatal de Docencia Universitaria, 2(2), 13-30. Recuperado de http://revistas.um.es/redu/article/view/20051

Dochy, F., Segers, M., \& Sluijsmans, D. (1999). The Use of Self-, Peer and Co-assessment in Higher Education: a review. Studies in Higher Education, 24(3), 331-350.

Fraile-Aranda, A., Catalina-Sancho, J., De diego-Vallejo, R., \& Aparicio-Herguedas, J. (2018). Las capacidades cognitivas en la evaluación de la formación inicial del profesorado de Educación Física. Sportis. Scientific Journal of School Sport, Physical Education and Psychomotricity, 4(1), 77-94. Recuperado de http://revistas.udc.es/index.php/SPORTIS/article/view/sportis.2018.4.1.3149

Gallardo, F., \& Carter, B. (2016). La evaluación formativa y compartida durante el prácticum en la formación inicial del profesorado: Análisis de un caso en Chile. Retos. Nuevas tendencias en Educación Física Deportes y Recreación, 29, 258-263. Recuperado de http://www.redalyc.org/ pdf/3457/345743464048.pdf

González, J., \& Wagenaar, R (2003). Tuning educational structures in Europe. I. Final report. Bilbao: 
Universidad de Deusto.

Gutiérrez, J., \& Cabero, J. (2016). Estudio de caso sobre la autopercepción de la competencia digital del estudiante universitario de las titulaciones de grado de Educación Infantil y Primaria. Profesorado. Revista de currículum y formación del profesorado, 20(2), 180-199. Recuperado de https://idus. us.es/xmlui/handle/11441/45324

Gutiérrez, M. (2017). Diseño de una experiencia de evaluación formativa mediante portafolio en el Grado en Magisterio de Educación Infantil en la Universidad de Cantabria. Revista Infancia, Educación y Aprendizaje, 3(2), 82-87. Recuperado de http://revistas.uv.cl/index.php/IEYA/article/ view/704

Hamodi, C., López, A., \& López-Pastor, V. (2014). Red de evaluación formativa y compartida en docencia universitaria: creación, consolidación y líneas de trabajo. REVALUE. Revista de Evaluación Educativa, 3(1). Recuperado de http://ojs.inee.edu.mx/revista/index.php/revalue/ article/view/110_

Hamodi, C., López-Pastor, V., \& López, A. (2017). If I experience formative assessment whilst at University will I put it into practice later as a teacher? Formative and shared assessment in Initial Teacher Education (ITE). European Journal of Teacher Education, 40(2), 171-190. doi:10.1080/ 02619768.2017.1281909.

Hawes, G., \& Corvalán, O. (2005). Construcción de un perfil profesional. Talca: Universidad de Talca.

Hortigüela-Alcalá, D., Abella-García, V., Delgado, V., \& Austin, V. (2016). Influencia del sistema de evaluación empleado en la percepción del alumno sobre su aprendizaje y las competencias docentes. Revista Infancia, Educación y Aprendizaje, 2(1), 20-42.

Hortigüela-Alcalá, D., Pérez-Pueyo, Á., \& Abella, V. (2015). ¿Cómo influye el sistema de evaluación en la percepción del alumnado? @ tic. revista d'innovació educativa, 14. 82-89.

Hortigüela-Alcalá, D., Pérez-Pueyo, Á., \& Abella, V. (2015). Perspectiva del alumnado sobre la evaluación tradicional y la evaluación formativa. Contraste de grupos en las mismas asignaturas. REICE. Revista Iberoamericana sobre Calidad, Eficacia y Cambio en Educación, 13(1). 35-48. Recuperado de http://www.redalyc.org/html/551/55133776003/

Hortigüela-Alcalá, D., Pérez-Pueyo, Á., \& López-Pastor, V. (2015). Implicación y regulación del trabajo del alumnado en los sistemas de evaluación formativa en educación superior. RELIEVE. Revista Electrónica de Investigación y Evaluación Educativa, 21(1), 1-15. Recuperado de https:// www.uv.es/RELIEVE/v21n1/RELIEVEv21n1_ME6.pdf

Ibarra-Sáiz, M., Rodríguez-Gómez, G., \& Gómez-Ruiz, M. (2012). La evaluación entre iguales: beneficios y estrategias para su práctica en la universidad. Revista de Educación, 359, 206-231.

Knight, P. (2005). El profesorado de Educación Superior. Formación para la excelencia. Madrid: Narcea.

López-Pastor, V. (2008). Desarrollando sistemas de evaluación formativa y compartida en la docencia universitaria. Análisis de resultados de su puesta en práctica en la formación inicial del profesorado. European Journal of Teacher Education, 31(3), 293-311. doi:http://dx.doi. org/10.1080/02619760802208452

López-Pastor, V. (Coord.). (2009). La Evaluación Formativa y Compartida en Educación Superior: propuestas, técnicas, instrumentos y experiencias. Narcea: Madrid.

López-Pastor, V. (2012). Evaluación Formativa y Compartida en la Universidad: clarificación de conceptos y propuestas de intervención desde la Red Interuniversitaria de Evaluación Formativa. Psychology, Society \& Educatión, 4(1), 117-130. Recuperado de http://repositorio.ual.es/ bitstream/handle/10835/2887/ vista\%20Lopez\%20Pastor.pdf?sequence $=1$

López-Pastor, V., Manrique, J., Monjas, R., \& Gea, J. (2010) Formative Assessment in project-oriented learning to improve academic performance. Assessment, Learning \& Teaching Journal, 9, 23-26. Recuperado de http://eprints.leedsbeckett.ac.uk/1103/1/Formative\%20assessment.pdf

López-Pastor, V., \& Pérez-Pueyo, Á. (Coord.). (2017). Evaluación formativa y compartida en educación: experiencias de éxito en todas las etapas educativas. León: Universidad de León. 
Estudios Pedagógicos XLIV, № 2: 55-77, 2018

EFECTOS DE LA APLICACIÓN DE UN SISTEMA DE EVALUACIÓN FORMATIVA EN LA AUTOPERCEPCIÓN DE COMPETENCIAS ADQUIRIDAS EN FORMACIÓN INICIAL DEL PROFESORADO

Recuperado de http://buleria.unileon.es/handle/10612/5999

López-Pastor, V., Pérez-Pueyo, A., Barba, J., \& Lorente, E. (2016). Percepción del alumnado sobre la utilización de una escala graduada para la autoevaluación y coevaluación de trabajos escritos en la formación inicial del profesorado de educación física (FIPEF). Cultura, ciencia y deporte, 11(31), 37-50. Recuperado de http://www.redalyc.org/pdf/1630/163044427005.pdf

Mas-Torelló, Ó., \& Olmos-Rueda, P. (2016). El profesor universitario en el Espacio Europeo de Educación Superior: la autopercepción de sus competencias docentes actuales y orientaciones para su formación pedagógica. Revista mexicana de investigación educativa, 21(69), 437-470.

Martín, P. (2007). Evaluación formativa y su repercusión en el clima del aula. Revista de Investigación educativa, 25(2), 389-402. Recuperado de http://revistas.um.es/rie/article/view/96851

Martínez-Mínguez, L. (2016). Proyectos de Aprendizaje Tutorados y autoevaluación de competencias profesionales en la formación inicial del profesorado. RETOS. Nuevas Tendencias en Educación Física, Deporte y Recreación, 29, 242-250. Recuperado de http://www.redalyc.org/ $\mathrm{html} / 3457 / 345743464046 /$

Manrique-Arribas, J., López-Pastor, V., Monjas, R., \& Real-Rubio, F. (2010). El potencial de los proyectos de aprendizaje tutorado y los sistemas de evaluación formativa en la mejora de la autonomía del alumnado. Una experiencia interdisciplinar en formación inicial del profesorado. Revista Española de Educación Física y Deportes, 14, 39-57. Recuperado de http://www.reefd.es/ index.php/reefd/article/viewFile/285/276

Manrique-Arribas, J., Vallés, C., \& Gea, J. (2012). Resultados generales de la puesta en práctica de 29 casos sobre el desarrollo de sistemas de evaluación formativa en docencia universitaria. PSYE Psychology, Society, \& Education, 4(1), 87-102. Recuperado de http://repositorio.ual.es/bitstream/ handle/10835/2889/vista\%20Manrique\%20Arribas.pdf?sequence=1

Molina, M., \& López-Pastor, V. (2017). La transferencia de la evaluación formativa y/o Compartida desde la formación inicial del profesorado de Educación física a la práctica real en educación primaria. Infancia, Educación y Aprendizaje (IEYA), 3(2), 626-631. Recuperado de http:// revistas.uv.cl/index.php/IEYA/index

Palacios, A., \& López-Pastor, V. (2013). Haz lo que yo digo, pero no lo que yo hago: sistemas de evaluación del alumnado en la formación inicial del profesorado. Revista de Educación, 361, 279-305.

Quezada, I. (2014). El modelo de educación por competencias y su impacto en la planificación estratégica de la Universidad de Talca (Chile). Revista Universitaria Ruta, 16(1), 7-18. Recuperado de http://revistas.userena.cl/index.php/ruta/ article/view/466

Rodrigo-Alsina, M., \& Almiron, N. (2013). Autopercepción de la adquisición de competencias de los estudiantes de periodismo. El caso de la Universitat Pompeu Fabra. Aula Abierta, 41(1), 99-110.

Romero-Martín, M., Castejón-Oliva, F., \& López-Pastor, V. (2015). Divergencias del alumnado y del profesorado universitario sobre las dificultades para aplicar la evaluación formativa. RELIEVE. Revista Electrónica de Investigación y Evaluación Educativa, 21(1). Recuperado de https://www. uv.es/RELIEVE/v21n1/RELIEVEv21n1_ME5.pdf

Romero-Martín, M., Castejón-Oliva, F., López-Pastor, V., \& Fraile-Aranda, A. (2017). Evaluación formativa, competencias comunicativas y TIC en la formación del profesorado. Comunicar: Revista Científica de Comunicación y Educación, 52, 73-82. doi:10.3916/C52-2017-07

Sánchez, J., Mirete, A., García, F., \& Hernández, F. (2013). Valoración de las TIC por los estudiantes universitarios y su relación con los enfoques de aprendizaje. Revista de investigación educativa, 31(2), 537-554.

Santos-Pastor, M., Martínez-Muñoz, L., \& López-Pastor, V. (Coord.). (2009). La innovación docente en el EEES: experiencias de evaluación formativa y compartida en la formación inicial del profesorado. Almería: Editorial Universidad de Almería.

Salcines-Talledo, I., González-Fernández, N., Ramírez-García, A., \& Martínez-Mínguez, L. (2017). Validación de la Escala de Autopercepción de Competencias Transversales y Profesionales 
de Estudiantes de Educación Superior. Profesorado. Revista de Curriculum y formación del Profesorado, (en prensa).

Stake, R. (2010). Qualitative research: Studying how things work. New York: Guilford Press.

Silva, I., \& López-Pastor, V. (2015). ¿Cómo vive el alumnado la evaluación en formación inicial del profesorado? @ tic. revista d'innovació educativa, 14, 90-100. Recuperado de http://www. redalyc.org/html/3495/349541425011/

Ureña-Ortín, N., \& Ruiz-Lara, E. (2012). Experiencia de evaluación formativa y compartida en el Máster Universitario en Formación del Profesorado de Educación Secundaria. Psychology, Society \& Education, 4(1), 29-44. Recuperado de http://ojs.ual.es/ojs/index.php/psye/article/view/552

Villamizar, G., Becerra, D., \& Delgado, A. (2016). Autopercepción de estudiantes de psicología sobre sus competencias en los campos laboral, educativo y salud. REXE. Revista de Estudios y Experiencias en Educación, 13(26), 151-167. Recuperado de http://www.rexe.cl/ojournal/index. $\mathrm{php} / \mathrm{rexe} / \mathrm{article} / \mathrm{view} / 39$

Zabalza, M. (2001). La enseñanza universitaria. El escenario y sus protagonistas. Madrid: Narcea.

Zabalza, M. (2003). Diseño curricular en la universidad. Competencias del docente universitario. Madrid: Narcea. 
